\title{
Estimativa do risco de sodificação de solos de Pernambuco pelo uso de águas salinas ${ }^{1}$
}

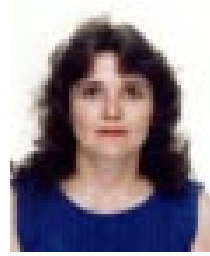

\author{
Maria B. G. dos S. Freire ${ }^{2}$, Hugo A. Ruiz ${ }^{3}$, Mateus R. Ribeiro ${ }^{4}$, Paulo A. Ferreira ${ }^{5}$, \\ Víctor H. Alvarez V. ${ }^{6}$ \& Fernando J. Freire ${ }^{7}$
}

\footnotetext{
1 Parte da Tese de Doutorado do primeiro autor, apresentada ao Programa de Pós-Graduação em Solos e Nutrição de Plantas da Universidade Federal de Viçosa, MG.

2 UFRPE/DEPA. Rua Dom Manoel de Medeiros s/n, Dois Irmãos, CEP 52171-900, Recife, PE. Fone: (81) 3302-1233. E-mail: mbetaniafreire@uol.com.br (Foto)

3 UFV/DPS. CEP 36571-000, Viçosa, MG. Fone: (31) 3899-1052. E-mail: hruiz@mail.ufv.br

4 UFRPE/DEPA. Fone: (81) 3302-1226. E-mail: rosas@truenet.com.br

5 UFV/DEA. Fone: (31) 3899-1911. E-mail: pafonso@mail.ufv.br

6 UFV/DPS. Fone: (31) 3899-1061. E-mail: vhav@mail.ufv.br

${ }^{7}$ UFRPE/DEPA. Fone: (81) 3302-1220. E-mail: ffreire@ufrpe.br
}

Protocolo 46 - 15/4/2002 - Aprovado em 30/7/2003

Resumo: Com o objetivo de se avaliar o risco de sodificação em solos irrigados com águas de diferentes condutividades elétricas (CE) e relações de adsorção de sódio (RAS), realizou-se um ensaio como permeâmetros de coluna vertical e carga constante. Os tratamentos corresponderam a nove amostras de solo e soluções percolantes com três CE $\left(175,500\right.$ e $\left.1.500 \mu \mathrm{S} \mathrm{cm}^{-1}\right)$ e seis RAS (de 0 a 30 para solos arenosos, de 0 a 25 para solos de textura média e de 0 a 15 para solos de textura argilosa). Inicialmente, realizou-se o ajuste da relação $\mathrm{Na}$ :Ca no complexo de troca catiônico dos solos, utilizando-se soluções na concentração de $50 \mathrm{mmol}_{\mathrm{c}} \mathrm{L}^{-1}$, nos níveis de RAS descritos; em seguida, iniciou-se a passagem das soluções de diferentes CE porém mesma RAS até escoamento permanente quando, então, os permeâmetros foram desmontados e as amostras analisadas. Determinaram-se o sódio trocável e a capacidade de troca de cátions das amostras e se calculou a relação de sódio trocável (RST) e a percentagem de sódio trocável (PST). Foram ajustadas equações relacionando-se a RST e a PST do solo com a CE e a RAS das soluções percolantes, em que o incremento da CE e da RAS elevou a RST e a PST dos solos. Os resultados demonstram que a correta avaliação dos riscos de sodificação deve levar em consideração as propriedades do solo e a qualidade da água.

Palavras-chave: condutividade elétrica, relação de adsorção de sódio, sódio trocável

\section{Estimation of sodification risks of Pernambuco soils in response to saline waters}

Abstract: An experiment was carried out in permeameters provided with vertical column and constant hydraulic head in order to evaluate sodification risks of soils with contrasting characteristics and treated with solutions of different electrical conductivities (EC) and sodium adsorption ratios (SAR). The treatments consisted of nine soils and eighteen percolating solutions with three EC values $\left(175,500\right.$ and $1,500 \mu \mathrm{Sm}^{-1}$ ) and six SAR values $(0$ to 30 for sandy soils, 0 to 25 for medium textured soils and 0 to 15 for clay textured soils). Initially, the adjustment of the $\mathrm{Na}$ : $\mathrm{Ca}$ ratio on the cation exchange complex of the soils was performed using solutions with concentration of $50 \mathrm{mmol}_{\mathrm{c}} \mathrm{L}^{-1}$. Later on leaching with solutions of different EC but same SAR was maintained to reach steady state flow, when the permeameters were dismantled and the soil samples removed for chemical analysis. Exchangeable sodium and cation exchange capacity were determined to calculate exchangeable sodium ratio (ESR) and exchangeable sodium percentage (ESP). Equations were adjusted between either ESR or ESP with EC and SAR of the percolating solution, the increment of EC and SAR elevated the soil ESR and the ESP. It may be concluded that the correct assessment of the sodification hazard has to take into consideration the soil properties and the water quality.

Key words: electrical conductivity, sodium adsorption ratio, exchangeable sodium 


\section{INTRODUÇÃO}

Solos de regiões áridas e semi-áridas podem apresentar acúmulo de sais e sódio trocável em níveis prejudiciais ao desenvolvimento das plantas, devido a processos naturais e antrópicos de salinização e sodificação, em conseqüência do manejo inadequado da irrigação. Em excesso, os sais prejudicam o crescimento das plantas, em virtude dos efeitos diretos sobre o potencial osmótico e dos íons potencialmente tóxicos presentes em elevadas concentrações na solução do solo. Por outro lado, o sódio trocável promove a degradação de algumas propriedades físicas do solo, reduzindo a infiltração da água e, conseqüentemente, dificultando o crescimento dos vegetais.

É oportuno um controle criterioso da água usada na irrigação, principalmente quando de baixa condutividade elétrica (CE) e relação de adsorção de sódio (RAS) mais elevada, o que favorece a dispersão dos colóides. A infiltração da água de chuva em solos salino-sódicos, por exemplo, poderá agravar os problemas próprios desses solos, ao lixiviar os sais solúveis e provocar a dispersão, promovendo redução na condutividade hidráulica (McNeal \& Coleman, 1966; Minhas \& Sharma, 1986).

Os cátions presentes na água, quando em equilíbrio com a fase sólida do solo, têm a capacidade de substituir outros cátions. Assim, na avaliação da qualidade de águas para irrigação é preciso se estabelecer, quantitativamente, a sodicidade resultante no solo irrigado, isto é, estimar a percentagem de sódio trocável (PST) associada à RAS da água a ser aplicada (Paliwal \& Gandhi, 1976).

Paliwal \& Gandhi (1976) propuseram equações que relacionam RST e RAS, separando os solos conforme a textura. Se fosse usada uma equação geral para o conjunto dos solos, o sódio trocável seria subestimado nos solos de textura grossa e superestimado nos de textura fina. Tal fato enfatiza a importância da textura em relação à estimativa da sodicidade do solo. A mineralogia é outro aspecto que deve ser levado em consideração.

Tem-se procurado relações entre a RST e a RAS da solução do solo, sem maior preocupação com a RAS da água utilizada na irrigação. $\mathrm{O}$ entendimento da forma pela qual a RST se relaciona com a RAS da água possibilitaria estimar-se a proporção do sódio no complexo de troca do solo, em decorrência do uso de diferentes águas, podendo-se evitar problemas de sodificação, tão sérios devido às dificuldades para corrigi-los.
É de grande importância o estudo da inter-relação entre o sódio no complexo de troca e a relação de adsorção de sódio da solução de equilíbrio, para prever e evitar a sodificação de solos com o uso de águas salinas e, também, estimar como essas trocas podem variar com as características próprias de cada solo. Desta forma, objetivou-se, neste trabalho, avaliar a saturação por sódio em solos de características diversas, tratados com soluções de diferentes condutividades elétricas e relações de adsorção de sódio.

\section{MATERIAL E MÉTODOS}

Foram utilizadas amostras de solo de horizontes selecionados de nove perfis representativos do Estado de Pernambuco (Ribeiro et al., 1999). O critério adotado para a escolha foi o de atender a uma gradação no teor de argila e a diferentes tipos de mineralogia. Para isto, foram coletadas e analisadas 16 amostras, selecionando-se nove: Neossolo Quartzarênico (Ibimirim/11-45 cm), Neossolo Regolítico (São Caetano/58-135 $\mathrm{cm}$ ), Neossolo Flúvico (Ibimirim/0-25 cm), Luvissolo Crômico (Serra Talhada/20-50 cm), Chernossolo Argilúvico (Nazaré da Mata/57-80 cm), Luvissolo Hipocrômico (Limoeiro/25-52 cm), Argissolo Vermelho-Amarelo (Riacho das Almas/35-68 cm), Planossolo Háplico (São Caetano/78-105 cm) e Argissolo Amarelo (Vertentes $/ 55-130 \mathrm{~cm}$ ). Na maioria dos casos, foram coletados horizontes sub-superficiais, visando evitar a interferência da matéria orgânica, exceto para o Neossolo Flúvico.

Após a coleta, as amostras foram secas ao ar, destorroadas e passadas em peneira de $2 \mathrm{~mm}$ para a caracterização física, química e mineralógica (Tabelas 1 e 2) e para a montagem do experimento. Na caracterização física, procedeu-se à análise granulométrica, utilizando-se $\mathrm{NaOH}$ como dispersante para os solos com pH inferior a 6,5, e o hexametafosfato de sódio $\left[\left(\mathrm{NaPO}_{3}\right)_{6}\right]$ para aqueles de $\mathrm{pH}$ superior a 6,5 (EMBRAPA, 1997). A separação de silte e argila foi realizada pelo método da pipeta. A densidade do solo foi determinada pelo método da proveta e a densidade das partículas, pelo método do balão volumétrico (EMBRAPA, 1997).

Determinou-se a capacidade de troca de cátions a $\mathrm{pH} 7,0$ pelo método do acetato de sódio/acetato de amônio (Richards, 1954). As análises foram realizadas com o solo lavado com etanol a 90\%, para evitar a interferência dos sais solúveis. Determinaram-se, ainda, os óxidos de ferro cristalinos e amorfos extraídos da fração argila com solução de ditionito-citrato-

Tabela 1. Análise granulométrica e densidades dos solos estudados de Pernambuco

\begin{tabular}{|c|c|c|c|c|c|c|c|c|}
\hline \multirow{3}{*}{ Solo } & \multirow{2}{*}{ Cascalho } & \multirow{2}{*}{$\begin{array}{l}\text { Terra } \\
\text { Fina }\end{array}$} & \multicolumn{2}{|c|}{ Areia } & \multirow{2}{*}{ Silte $^{1}$} & \multirow{2}{*}{ Argila $^{1}$} & \multicolumn{2}{|c|}{ Densidade } \\
\hline & & & Grossa $^{1}$ & Fina $^{1}$ & & & Solo & Partículas \\
\hline & \multicolumn{6}{|c|}{$\%$} & \multicolumn{2}{|c|}{$\mathrm{kg} \mathrm{dm}^{-3}$} \\
\hline Neossolo Quartzarênico & 0,4 & 99,6 & 77,0 & 17,4 & 0,8 & 4,8 & 1,67 & 2,63 \\
\hline Neossolo Regolítico & 9,4 & 90,6 & 52,6 & 20,8 & 14,6 & 12,0 & 1,65 & 2,60 \\
\hline Neossolo Flúvico & 0,4 & 99,6 & 12,7 & 45,1 & 28,8 & 13,4 & 1,45 & 2,56 \\
\hline Luvissolo Crômico & 9,6 & 90,4 & 41,9 & 23,3 & 18,3 & 16,5 & 1,46 & 2,63 \\
\hline Chernossolo Argilúvico & 0,8 & 99,2 & 21,9 & 27,7 & 27,4 & 23,0 & 1,28 & 2,78 \\
\hline Luvissolo Hipocrômico & 0,7 & 99,3 & 17,5 & 25,7 & 22,2 & 34,6 & 1,35 & 2,53 \\
\hline Argissolo Vermelho-Amarelo & 12,0 & 88,0 & 26,1 & 15,8 & 20,2 & 37,9 & 1,29 & 2,56 \\
\hline Planossolo Háplico & 7,4 & 92,6 & 38,9 & 9,7 & 9,0 & 42,4 & 1,34 & 2,63 \\
\hline Argissolo Amarelo & 5,9 & 94,1 & 15,1 & 7,3 & 13,1 & 64,5 & 1,18 & 2,67 \\
\hline
\end{tabular}

${ }^{1}$ Proporção na terra fina 
bicarbonato (Mehra \& Jackson, 1960) e oxalato de sódio (Schwertmann, 1964), respectivamente, sendo o ferro dosado por espectrofotometria de absorção atômica. Realizou-se, também, a análise mineralógica da fração argila por difração de raios X (Whitting \& Allardice, 1986).

Tabela 2. Capacidade de troca de cátions (CTC), ferro oxalato $\left(\mathrm{Fe}_{\mathrm{o}}\right)$, ferro ditionito $\left(\mathrm{Fe}_{\mathrm{d}}\right)$ e composição mineralógica da fração argila dos solos estudados de Pernambuco

\begin{tabular}{|c|c|c|c|c|}
\hline Solo & $\begin{array}{c}\text { CTC } \\
\mathrm{cmol}_{\mathrm{c}} \mathrm{dm}^{-3}\end{array}$ & $\frac{\mathrm{Fe}_{\mathrm{o}}}{\text { dag }}$ & & Mineralogia $^{1}$ \\
\hline Neossolo Quartzarêni & 2,05 & 0,68 & 2,30 & $\mathrm{Ct}$ \\
\hline Neossolo Regolítico & 5,65 & 0,14 & 0,19 & $\mathrm{t}>\mathrm{It}>\mathrm{Qz}$ \\
\hline Neossolo Flúvico & 22,40 & 0,29 & 1,75 & $\mathrm{It}>\mathrm{Et}>\mathrm{Ct}$ \\
\hline Luvissolo Crômica & 18,42 & 0,64 & 7,86 & $\mathrm{Ct}>\mathrm{Et}>\mathrm{Gh}>\mathrm{Hm}$ \\
\hline Che & 27,56 & 0,32 & 3,61 & $\mathrm{Et}>\mathrm{Ct}>\mathrm{Gh}$ \\
\hline Luvi & 25,72 & 0,14 & 0,99 & $\mathrm{Ct}=\mathrm{Et}>\mathrm{It} / \mathrm{Et}$ \\
\hline Argissolo Vermelho-Amarelo & 10,23 & 0,16 & 5,19 & $\mathrm{Ct}>\mathrm{It}>\mathrm{Gh}$ \\
\hline Planossolo Háplico & 15,32 & 0,16 & 0,38 & $\mathrm{Ct}>\mathrm{It}$ \\
\hline Argissolo Amarelo & 15,76 & 0,13 & 3,28 & $\mathrm{Ct}>\mathrm{It}>\mathrm{Gh}$ \\
\hline
\end{tabular}

${ }^{1}$ Ct: caulinita, It: Ilita, Qz: quartzo, Et: Esmectita, Gh: goethita, Hm: hematita, It/Et: interestratificado ilita/esmectita

Os tratamentos corresponderam a nove solos e dezoito soluções de percolação com três valores de CE e seis valores de RAS, em três repetições, dispostos em um delineamento em blocos casualizados.

O ajuste da relação Na:Ca no complexo de troca catiônica foi realizado em permeâmetros de carga constante, sendo o solo acondicionado cuidadosamente nas colunas, no valor da densidade do solo, até uma altura de $6 \mathrm{~cm}$ (Freire, 2001).

Com grande número de unidades experimentais (nove solos, três CE, seis RAS e três repetições) totalizando 486 permeâmetros, o experimento foi montado considerando-se um bloco de cada vez; entretanto, seguiu-se rigorosamente a mesma sequiência dentro dos blocos, montando-se os permeâmetros de todos os tratamentos de cada solo por vez, até completar o bloco, para só depois se iniciar o bloco seguinte.

As soluções utilizadas para o ajuste da relação $\mathrm{Na}: \mathrm{Ca}$ (soluções saturantes) foram preparadas de forma a se chegar a uma concentração final de $50 \mathrm{mmol}_{\mathrm{c}} \mathrm{L}^{-1}$. Para isto, misturaramse soluções de $\mathrm{NaCl}$ e de $\mathrm{CaCl}_{2}$, de concentração apropriada, que possibilitaram alcançar os valores de RAS estabelecidos para cada tratamento: 0 a 30 para solos arenosos, 0 a 25 para solos de textura média e 0 a 15 para solos de textura argilosa/ muito argilosa (Freire, 2001).

As colunas foram colocadas para saturar dentro de recipientes cilíndricos de plástico, contendo a solução saturante, conforme o tratamento, até uma altura correspondente a dois terços da altura da amostra de solo $(4 \mathrm{~cm})$ e assim permaneceram durante $48 \mathrm{~h}$, quando foram montados os permeâmetros de coluna vertical e carga constante (Ferreira, 1999). A solução saturante foi aplicada até o momento em que a condutividade elétrica do efluente se aproximou daquela da solução aplicada. $\mathrm{O}$ volume aplicado de solução equivaleu a aproximadamente 50 vezes o volume de poros de cada solo na coluna; posteriormente, as colunas de solo foram mantidas em recipientes com as soluções saturantes, por mais $24 \mathrm{~h}$.
Após a finalização do ajuste da relação $\mathrm{Na}: \mathrm{Ca}$, os permeâmetros foram remontados para a aplicação das soluções percolantes, nos mesmos valores de RAS das anteriores e com $\mathrm{CE}$ de $175,500 \mathrm{e} 1.500 \mu \mathrm{S} \mathrm{cm}^{-1}$. As soluções foram aplicadas nas colunas utilizando-se o sistema do "frasco de Mariotte", para manutenção de carga hidráulica constante (Ferreira, 1999). Como as amostras estavam saturadas com uma solução concentrada $\left(50 \mathrm{mmol}_{\mathrm{c}} \mathrm{L}^{-1}\right)$, a percolação foi mantida até atingir o escoamento permanente, ou seja, quando ocorreu o equilíbrio entre a solução e a matriz do solo.

Concluído o ensaio, as amostras foram retiradas das colunas dos permeâmetros, colocadas para secar ao ar, destorroadas e passadas em peneira de $2 \mathrm{~mm}$, analisando-se o sódio trocável, segundo método previamente indicado. Foram calculadas a relação de sódio trocável (RST) e a percentagem de sódio trocável (PST) pelas Eqs. 1 e 2, respectivamente.

$$
\begin{aligned}
\mathrm{RST} & =\frac{\mathrm{Na}}{\mathrm{CTC}-\mathrm{Na}} \\
\mathrm{PST} & =\frac{\mathrm{Na}}{\mathrm{CTC}} 100
\end{aligned}
$$

em que Na é a concentração de sódio trocável, em $\mathrm{cmol}_{\mathrm{c}} \mathrm{kg}^{-1} \mathrm{e}$ CTC é a capacidade de troca de cátions, em $\mathrm{cmol}_{\mathrm{c}} \mathrm{kg}^{-1}$.

As variáveis estudadas (RST e PST) foram submetidas à análise de variância, com agrupamento dos solos conforme a homogeneidade de variância. Determinaram-se superfícies de respostas, relacionando-se as variáveis com a CE e a RAS da solução de percolação. Escolheu-se o modelo com maior coeficiente de determinação ajustado que apresentasse parâmetros significativos até $10 \%$, pelo teste t.

\section{RESULTADOS E DISCUSSÃO}

O uso de soluções de diferentes valores de RAS proporcionou alterações na RST e na PST. Todos os solos apresentaram elevação da RST e da PST pela aplicação de soluções de RAS crescente, caracterizando a saturação do complexo de troca catiônico do solo pelo sódio aplicado na forma solúvel (Tabela 3).

Para se estimar a sodicidade resultante do uso de soluções com sais e sódio, calcularam-se superfícies de resposta entre a RST do solo e a CE e a RAS da solução aplicada. Em todos os solos, o aumento da RST foi influenciado pela CE e pela RAS da solução percolante, sem se registrar efeito de interação entre as duas variáveis independentes (Tabela 4A).

As superfícies de resposta se ajustaram bem na estimativa da RST dos solos com os valores de CE e RAS das soluções aplicadas, com coeficientes dos parâmetros significativos, podendo ser usados para estimar a RST resultante do uso de águas contendo sais e sódio para os solos estudados, mas cada solo tem um modelo de ajuste próprio, demonstrando o comportamento diferenciado entre eles, quanto a sodicidade. 
Tabela 3. Relação de sódio trocável (RST) das amostras de solo, considerando a condutividade elétrica e a relação de adsorção de sódio (RAS) da solução percolante ${ }^{1}$

\begin{tabular}{|c|c|c|c|c|c|c|c|c|c|}
\hline $\begin{array}{c}\text { Nível } \\
\text { da RAS }\end{array}$ & $\begin{array}{l}\text { Neossolo } \\
\text { Quartz.8 }\end{array}$ & $\begin{array}{l}\text { Neossolo } \\
\text { Regolítico }\end{array}$ & $\begin{array}{l}\text { Neossolo } \\
\text { Flúvico }\end{array}$ & $\begin{array}{l}\text { Luvissolo } \\
\text { Crômico }\end{array}$ & $\begin{array}{l}\text { Chernosolo. } \\
\text { Argilúvico }\end{array}$ & $\begin{array}{l}\text { Luvissolo } \\
\text { Hipocr. }\end{array}$ & $\begin{array}{c}\text { Argissolo } \\
\text { Verm.-Amar. }\end{array}$ & $\begin{array}{l}\text { Planossolo } \\
\text { Háplico }\end{array}$ & $\begin{array}{c}\text { Argissolo } \\
\text { Amarelo }\end{array}$ \\
\hline & \multicolumn{9}{|c|}{$\%$} \\
\hline & \multicolumn{9}{|c|}{ Condutividade Elétrica $175 \mu \mathrm{S} \mathrm{cm}^{-1}$} \\
\hline 1 & 0,0707 & 0,0289 & 0,0082 & 0,0057 & 0,0062 & 0,0086 & 0,0132 & 0,0176 & 0,0108 \\
\hline 2 & 0,1086 & 0,0610 & 0,0356 & 0,0326 & 0,0462 & 0,0493 & 0,0379 & 0,0435 & 0,0320 \\
\hline 3 & 0,1268 & 0,0675 & 0,0641 & 0,0605 & 0,0934 & 0,1038 & 0,0475 & 0,0568 & 0,0459 \\
\hline 4 & 0,1390 & 0,0739 & 0,0960 & 0,0842 & 0,1453 & 0,1612 & 0,0551 & 0,0659 & 0,0520 \\
\hline 5 & 0,1610 & 0,0830 & 0,1293 & 0,1098 & 0,1907 & 0,2161 & 0,0615 & 0,0725 & 0,0596 \\
\hline 6 & 0,1866 & 0,0932 & 0,1596 & 0,1363 & 0,2285 & 0,2679 & 0,0680 & 0,0859 & 0,0724 \\
\hline \multicolumn{10}{|c|}{ Condutividade Elétrica $500 \mu \mathrm{S} \mathrm{cm}^{-1}$} \\
\hline 1 & 0,0847 & 0,0265 & 0,0094 & 0,0064 & 0,0070 & 0,0090 & 0,0143 & 0,0178 & 0,0115 \\
\hline 2 & 0,1695 & 0,0696 & 0,0441 & 0,0377 & 0,0543 & 0,0560 & 0,0453 & 0,0490 & 0,0391 \\
\hline 3 & 0,1643 & 0,0860 & 0,0710 & 0,0634 & 0,0928 & 0,1065 & 0,0594 & 0,0658 & 0,0563 \\
\hline 4 & 0,1767 & 0,0951 & 0,0943 & 0,0914 & 0,1413 & 0,1621 & 0,0736 & 0,0797 & 0,0749 \\
\hline 5 & 0,1998 & 0,1101 & 0,1273 & 0,1199 & 0,1926 & 0,2172 & 0,0835 & 0,0913 & 0,0843 \\
\hline 6 & 0,2125 & 0,1131 & 0,1499 & 0,1475 & 0,2339 & 0,2672 & 0,0906 & 0,1052 & 0,0988 \\
\hline \multicolumn{10}{|c|}{ Condutividade Elétrica $1.500 \mu \mathrm{S} \mathrm{cm}^{-1}$} \\
\hline 1 & 0,0540 & 0,0264 & 0,0091 & 0,0064 & 0,0071 & 0,0087 & 0,0146 & 0,0186 & 0,0106 \\
\hline 2 & 0,1206 & 0,0792 & 0,0482 & 0,0445 & 0,0543 & 0,0665 & 0,0519 & 0,0532 & 0,0463 \\
\hline 3 & 0,1661 & 0,1035 & 0,0776 & 0,0721 & 0,1052 & 0,1239 & 0,0705 & 0,0723 & 0,0697 \\
\hline 4 & 0,2223 & 0,1240 & 0,1109 & 0,1023 & 0,1562 & 0,1784 & 0,0951 & 0,0969 & 0,0969 \\
\hline 5 & 0,2294 & 0,1398 & 0,1352 & 0,1315 & 0,2181 & 0,2343 & 0,1104 & 0,1058 & 0,1159 \\
\hline 6 & 0,2791 & 0,1514 & 0,1654 & 0,1494 & 0,2615 & 0,2772 & 0,1319 & 0,1301 & 0,1359 \\
\hline
\end{tabular}

${ }^{1} \mathrm{O}$ respectivo valor de porcentagem de sódio trocável (PST) pode ser obtido mediante relação PST = 100 (RST/1 + RST)

Tabela 4. Superfícies de resposta para relação de sódio trocável (RST) (A) e percentagem de sódio trocável (PST) (B) em função da condutividade elétrica (CE em $\mu \mathrm{S} \mathrm{cm}^{-1}$ ), e a relação de adsorção de sódio (RAS) das soluções percolantes

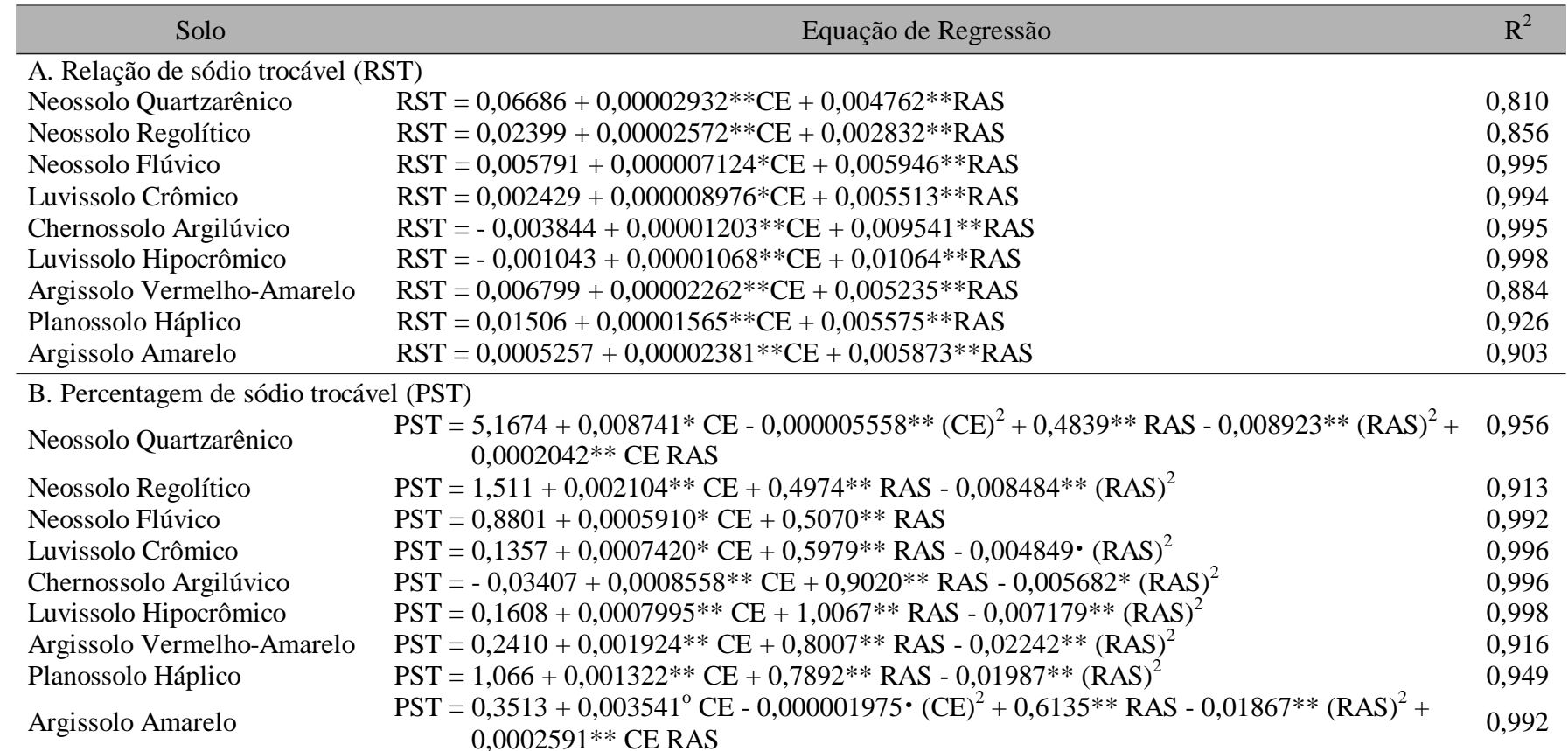

* e ** - Significativos a 10,5 e $1 \%$, respectivamente, pelo teste $\mathrm{t}$

O critério mais utilizado para se estimar a tendência a dispersividade e a instabilidade de agregados tem sido a PST. Para PST alta, a CE mínima para preservar a estrutura dos agregados deve, também, ser elevada; caso contrário, podem ocorrer reduções na permeabilidade e drenagem do solo, deficiência de aeração, encrostamento superficial e processos de contração e expansão sob ciclos de umedecimento e secagem (McBride, 1994).
Os valores da PST foram relacionados com a CE e a RAS dos tratamentos impostos, ajustando-se superfícies de resposta (Tabela 4B). A Figura 1 apresenta cortes nas superfícies de resposta ajustadas, correspondentes aos três valores da $\mathrm{CE}$ e, nelas, observa-se que quatro solos apresentam uma resposta diferente daquela dos cinco restantes. O primeiro grupo é integrado pelas amostras de Neossolo Flúvico, Luvissolo Crômico, Chernossolo Argilúvico e Luvissolo Hipocrômico, e 

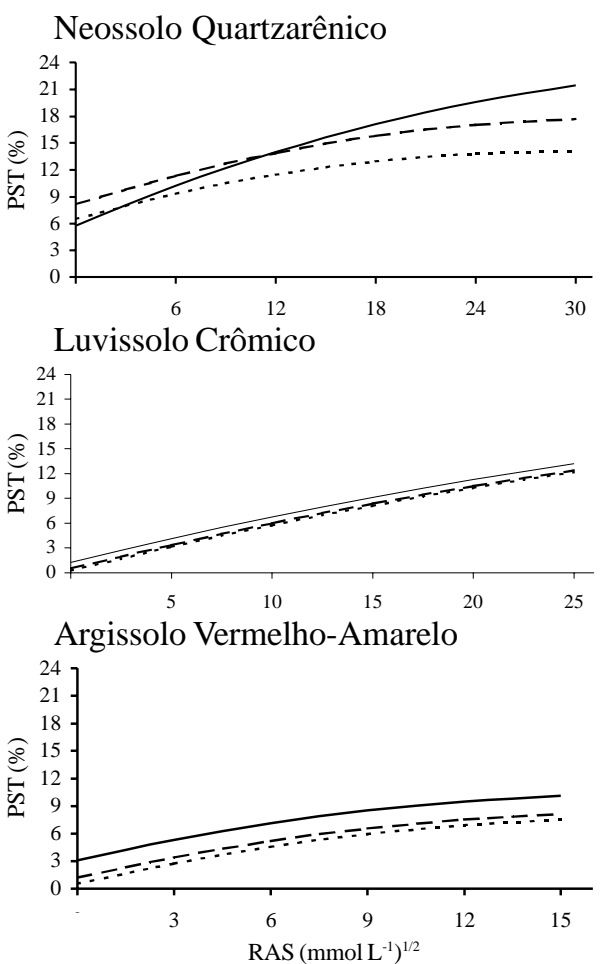

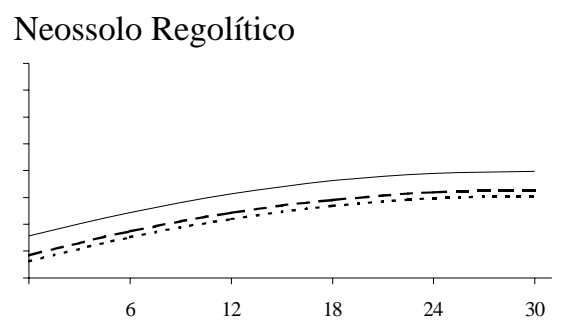

Chernossolo Argilúvico

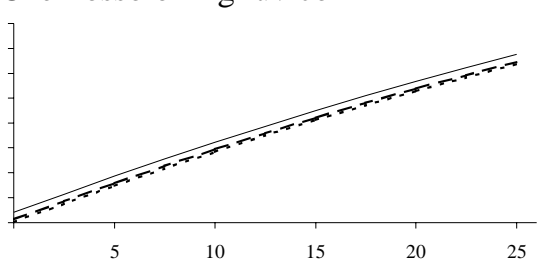

Planossolo Háplico

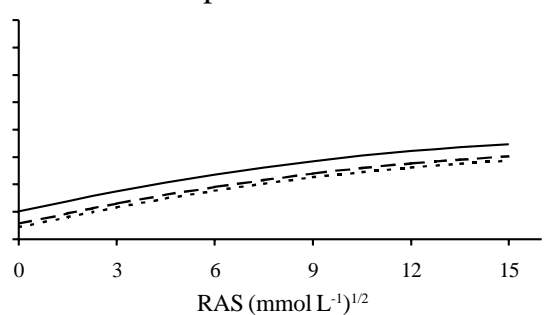

Neossolo Flúvico

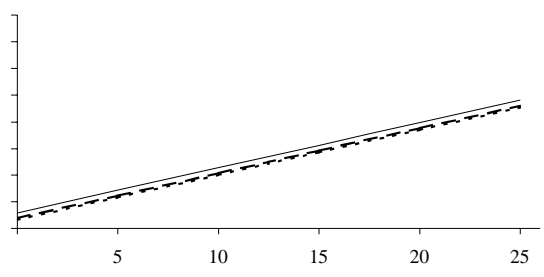

Luvissolo Hipocrômico

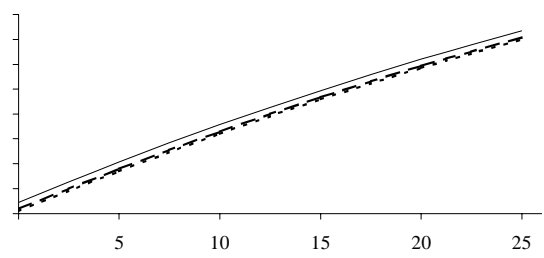

Argissolo Amarelo

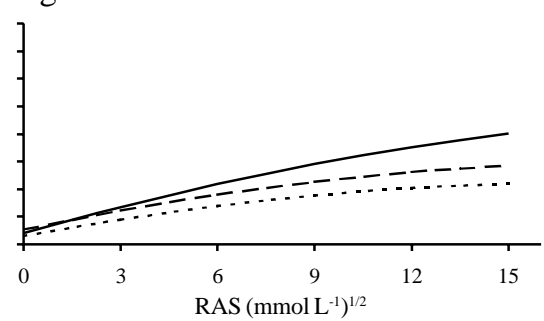

Figura 1. Percentagem de sódio trocável (PST) em função da relação de adsorção de sódio (RAS) de soluções percolantes em diferentes solos estudados de Pernambuco. Curvas determinadas por cortes nas superfícies de resposta para condutividades elétricas de $175(\ldots \ldots .),. 500(-)$ e $1.500 \mu \mathrm{S} \mathrm{cm}^{-1}(-)$ respectivamente

o segundo corresponde aos solos Neossolo Quartzarênico, Neossolo Regolítico, Argissolo Vermelho-Amarelo, Planossolo Háplico e Argissolo Amarelo.

Nas superfícies de resposta do Neossolo Flúvico, do Luvissolo Crômico, do Chernossolo Argilúvico e do Luvissolo Hipocrômico, a contribuição da CE para a PST é inferior à dos demais solos e não houve interação significativa entre CE e RAS (Tabela 4B); assim, as curvas para as três CE de trabalho aparecem praticamente superpostas. Esses quatro solos apresentaram, em geral, valores reduzidos de condutividade hidráulica em meio saturado $\left(0,23,1,96,0,88\right.$ e $0,52 \mathrm{~cm} \mathrm{~h}^{-1}$, respectivamente), o que permitiu maior contato entre a solução de trabalho e os cátions adsorvidos no complexo de troca do solo. Este fato, independentemente da concentração eletrolítica, teria levado ao equilíbrio entre o sódio trocável e o sódio em solução, justificando o paralelismo e a proximidade das três curvas correspondentes a cada solo.

O comportamento diferenciado do Argissolo VermelhoAmarelo, do Planossolo Háplico e do Argissolo Amarelo, com relação aos quatro solos previamente citados, pode ser atribuído aos maiores valores da condutividade hidráulica em meio

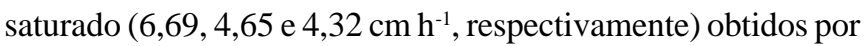
Freire et al. (2003); assim, a solução com maior condutividade elétrica $\left(1.500 \mu \mathrm{S} \mathrm{cm}^{-1}\right)$ aproxima-se mais rapidamente do equilíbrio com o sódio no complexo de troca.

O Neossolo Quartzarênico mostrou a interação apontada com comportamento semelhante ao do Argissolo Amarelo (Figura 1). Este solo apresentou condutividade hidráulica excessiva, de $83,65 \mathrm{~cm} \mathrm{~h}^{-1}$ (Freire et al., 2003) o que impossibilitou que o equilíbrio fosse atingido. A resposta do Neossolo Regolítico não tem uma justificativa tão evidente, pois apresentou reduzidos valores de condutividade hidráulica em meio saturado $\left(0,84 \mathrm{~cm} \mathrm{~h}^{-1}\right)$ e do teor de argila (Tabela 1$)$.

Além do tempo de contato, a mineralogia também poderia explicar esse comportamento diferenciado para os dois grupos de solo. Observa-se que os quatro solos do primeiro grupo apresentam esmectita em sua mineralogia, enquanto os demais são predominantemente cauliníticos (Tabela 2), podendo demonstrar maior afinidade da esmectita no processo de saturação por sódio (Barzegar et al., 1997), com pouca interferência da CE da água utilizada. Caso esta hipótese seja verídica, solos dominados por caulinita suportariam águas de RAS mais elevada, desde que a CE fosse baixa, antes de ser deflagrado o processo de sodificação, mas tal comportamento precisa ser estudado mais detalhadamente, para melhor conhecimento do fenômeno.

\section{CONCLUSÕES}

1. O incremento da condutividade elétrica e da relação de adsorção de sódio das soluções utilizadas elevou a relação de sódio trocável (RST), e a percentagem de sódio trocável (PST), indicando saturação crescente de sódio nesses solos.

2. O comportamento dos solos foi diferenciado em relação à saturação por sódio com os tratamentos aplicados, indicando a necessidade do conhecimento de cada solo, para a correta estimativa da RST e da PST resultante do uso de águas salinas na agricultura irrigada.

\section{AGRADECIMENTOS}

Ao Departamento de Agronomia da Universidade Federal Rural de Pernambuco pela colaboração e apoio nos trabalhos 
de coleta e preparo das amostras de solo, e uso dos laboratórios para a realização de parte das análises.

\section{LITERATURA CITADA}

Barzegar, A.R.; Nelson, P.N.; Oades, J.M.; Rengasamy, P. Organic matter, sodicity, and clay type: Influence on soil aggregation. Soil Science Society of America Journal, Madison, v.61, p.1131-1137, 1997.

EMBRAPA - Empresa Brasileira de Pesquisa Agropecuária. Manual de métodos de análise de solo. Rio de Janeiro, Centro Nacional de Pesquisa de Solos, 1997. 212p.

Ferreira, P.A. Drenagem de terras agrícolas. Viçosa: Universidade Federal de Viçosa/Departamento de Engenharia Agrícola, 1999. 187p.

Freire, M.B.G. dos S. Saturação por sódio e qualidade da água de irrigação na degradação de propriedades físicas de solos do Estado de Pernambuco. Viçosa: Universidade Federal de Viçosa, 2001. 66p. Tese Doutorado

Freire, M.B. dos S.; Ruiz, H.A.; Ribeiro, M.R.; Ferreira, P.A.; Alvarez, V.H.; Freire, J.F. Condutividade hidráulica de solos de Pernambuco em resposta à condutividade elétrica e RAS da água de irrigação. Campina Grande: Revista Brasileira de Engenharia Agrícola e Ambiental, v.7, n.1, p.45-52, 2003.

McBride, M.B. Environmental chemistry of soils. Oxford: Oxford University Press, 1994. 406p.

McNeal, B.L.; Coleman, N.T. Effect of solution composition on soil hydraulic conductivity. Soil Science Society of America Proceedings, Madison, v.30, p.308-312, 1966.
Mehra, O.P.; Jackson, M.L. Iron oxide removal from clays by dithionite-citrate-bicarbonate system buffered with sodium bicarbonate. Clays and Clay Minerals, Denvers, v.7, p.317327,1960

Minhas, P.S.; Sharma, D.R. Hydraulic conductivity and clay dispersion as affected by application sequence of saline and simulated rain water. Irrigation Science, Berlin, v.63, p.159-167, 1986.

Paliwal, K.V.; Gandhi, A.P. Effect of salinity, SAR, Ca:Mg ratio in irrigation water, and soil texture on the predictability of exchangeable sodium percentage. Soil Science, Baltimore, v.122, p.85-90, 1976.

Ribeiro, M.R.; Jacomine, P.K.T.; Ferreira, M.G.V.X.; Rodrigues, J.J.V.; Lima, J.F.W.F. Caracterização e classificação de solos de referência do Estado de Pernambuco. Recife: Universidade Federal Rural de Pernambuco, 1999. Relatório do Projeto Integrado CNPq/FACEPE, Processo 523205/96-1

Richards, L.A. Diagnosis and improvement of saline and alkali soils. Washington: US Department of Agriculture, 1954. 160p. USDA Agricultural Handbook, 60

Schwertmann, $\mathrm{W}$. The differentiation of iron oxide in soils by a photochemical extraction with acid ammonium oxalate. $Z$. Pflanzenernahr. Dung. Bodenkunde, v.15, p.194-201, 1964.

Whitting, L.D.; Allardice, W.R. X-ray diffraction techniques. In: Klute, A. (ed.). Methods of soil analysis. Part 1. Physical and mineralogical methods. Madison: Soil Science Society of America, 1986. p.331-359. 